\title{
What does it mean to be genomically literate?: National Human Genome Research Institute Meeting Report
}

\author{
Belen Hurle, PhD', Toby Citrin, JD², Jean F. Jenkins, $\mathrm{PhD}^{3}$, Kimberly A. Kaphingst, ScD ${ }^{4}$, \\ Neil Lamb, PhD ${ }^{5}$, Jo Ellen Roseman, $\mathrm{PhD}^{6}$ and Vence L. Bonham, JD ${ }^{1}$
}

Genomic discoveries will increasingly advance the science of medicine. Limited genomic literacy may adversely impact the public's understanding and use of the power of genetics and genomics in health care and public health. In November 2011, a meeting was held by the National Human Genome Research Institute to examine the challenge of achieving genomic literacy for the general public, from kindergarten to grade 12 to adult education. The role of the media in disseminating scientific messages and in perpetuating or reducing misconceptions was also discussed. Workshop participants agreed that genomic literacy will be achieved only through active engagement

The wider use of genomic approaches in health care and public health is one of the greatest medical accomplishments of our era. With the explosive growth of genomic approaches to health care comes the realization that current approaches to genetic and genomic education do not adequately prepare the public to understand personal health issues involving genomic medicine, understand media reports about advancement of genomic research, or participate in public policy discussions relating to the role of genomics in society. ${ }^{1}$ Even the very definition of "genomics" versus "genetics," or of what constitutes a "genomically literate public" remains to be fully articulated.

On 17-18 November 2011, the National Human Genome Research Institute at the National Institutes of Health held a workshop in Rockville, MD, to focus on genomic literacy, which was defined as the working knowledge of genomic science and its role in society, including personal decision making, participation in civic and cultural affairs, and economic productivity. Different facets of genomic literacy that were discussed included genomic health literacy and genomic science literacy. Borrowing directly from the concept of health literacy, ${ }^{2}$ genomic health literacy was defined as the capacity to obtain, process, understand, and use genomic information for health-related decision making. Likewise, based on the concept of scientific literacy, ${ }^{3}$ genomic science literacy was defined as the knowledge of basic genetics and genomic concepts and processes needed to build conceptual understanding, and the necessary mathematical knowledge to support this comprehension. The workshop was attended by 50 participants (see Supplementary Table S1 between genomics experts and the varied constituencies that comprise the public. This report summarizes the background, content, and outcomes from this meeting, including recommendations for a research agenda to inform decisions about how to advance genomic literacy in our society.

Genet Med 2013:15(8):658-663

Key Words: genomic literacy; genomics; National Human Genome Research Institute; public health genomics

online) from multiple sectors, including academia, state and federal government, kindergarten to grade 12 (K-12) education, community-based organizations, advocacy, and consumers, all interested in promoting public understanding of the role of genomics in human health and society. This meeting was organized to explore the following topics:

1. To define what is known and what needs to be known about the public's current knowledge in genetics and genomics;

2. To define what the public needs to understand about genetics and genomics to make health-care decisions and to be informed citizens;

3. To identify research opportunities for studying the genomic literacy of the public;

4. To identify strategies to engage diverse communities to increase genetic and genomic literacy.

To provide attendees with an overview of the kinds of knowledge that the public will need, the director of the National Human Genome Research Institute, Eric D. Green, MD, PhD, opened the workshop by presenting the 2011 Institute's genomic strategic plan. ${ }^{4}$ This strategic vision is organized around five domains of research activities that together chart a progression from basic research, to elucidating the structure and biology of genomes, to understanding the biology of disease and advancing the science of medicine. The ultimate goal, of course, was to improve the effectiveness of health care and advance human health. Significantly, three major crosscutting domains

\footnotetext{
${ }^{1}$ Division of Policy, Communications and Education, National Human Genome Research Institute, National Institutes of Health, Bethesda, Maryland, USA; ${ }^{2}$ Center for Public Health and Community Genomics, Department of Health Management and Policy, University of Michigan School of Public Health, Ann Arbor, Michigan, USA; ${ }^{3}$ Genomic Healthcare Branch, National Human Genome Research Institute, National Institutes of Health, Bethesda, Maryland, USA; ${ }^{4}$ Department of Surgery, Division of Public Health Sciences, Washington University School of Medicine, St. Louis, Missouri, USA; ${ }^{5}$ HudsonAlpha Institute for Biotechnology, Huntsville, Alabama, USA; ${ }^{6}$ American Association for the Advancement of Science, Washington, DC, USA. Correspondence: Belen Hurle (bhurle@mail.nih.gov)
} 
identified in the strategic plan are computational biology, education and training, and genomics and society, the latter two underscoring the importance of promoting public understanding of the role of genomics in human health and other areas.

The participants agreed that acquiring adequate genomic science education in $\mathrm{K}-12$ is needed as a means to increase long-term genomic health literacy in our society. Therefore, the genomic literacy challenges faced by the public were considered from K-12 and adult perspectives as a way to highlight the gaps, intersections, and areas of opportunity for studying genomic health and genomic science literacy in an integrated fashion (Supplementary Table S2 online). The role of the media in disseminating scientific messages and in perpetuating or reducing misconceptions was also discussed.

Involving the community in decision-making processes and collaborating with its members are cornerstones of efforts to improve public health and to engage communities to address health inequities. ${ }^{5,6}$ Although a significant effort has been invested in researching the health literacy skills and needs of the public, ${ }^{7}$ the perspectives of lay communities on genomic health and genomic science literacy have been explored to a lesser degree. ${ }^{8}$ Thus, community-based input was included in the workshop in two ways: in the form of reports from two shortterm community engagement projects identified as Community Conversations, that explored community opinions and attitudes about their constituency's genomic health literacy needs; and from focus groups held with formal and informal K-12 educators that summarized their perspectives on the importance of genomic science literacy for themselves and their students.

This background information was the foundation for subsequent breakout sessions to identify research opportunities for studying (i) genomic health literacy of the public, (ii) genomic science literacy for K-12 audiences, and (iii) the role of media in genomic literacy. A major outcome of this session was to provide the scope and priorities for a genomic literacy research agenda.

\section{THE CHALLENGE OF GENOMIC HEALTH LITERACY}

Deborah Bowen, PhD, of Boston University (Supplementary Table S1 online), opened the Genomic Health Literacy session by describing the challenge of achieving genomic health literacy for the general public. Genomic science has identified grand medical challenges such as making genomics-based diagnostic tests routine, achieving a comprehensive characterization of cancer genomes, and incorporating genomic data into personalized medical treatment. ${ }^{4}$ Rapidly expanding research in epigenetics is illuminating the impact of the environment on gene expression. These significant scientific achievements contrast sharply with the public's level of understanding of basic biology (including genetics) ${ }^{9}$ and mathematics (including probability theory, statistics, and risk)..$^{10}$ These concepts are important to allow the public to integrate genomics into their personal health care. ${ }^{11}$ Current models provide genomic risk estimates for groups of people, but statistical methods need further improvement to better predict individual genetic risk. The statistical and mathematical knowledge of the public are inadequate to support the needed understanding of concepts such as absolute and relative genetic disease risk..$^{10}$ Furthermore, the public does not usually receive actionable information in the form of individualized risk management plans. Arguably, when genomic risk information is presented in a way that people cannot understand at their skill and/or linguistic level, it is unlikely to impact behavior, or it may change people's behavior in unintended ways but not ultimately improve health or environmental outcomes. ${ }^{12-14}$ Likewise, people may lack a conceptual framework to deal with the range of potential findings that might be disclosed by genetic testing, such as carrier status for diseases uncovered through sequencing. ${ }^{15}$ Compounding the problem, health-care providers are not adequately trained to support the use of personalized disease risk and treatment information toward the public health good. ${ }^{16,17}$ The workshop participants contended that the collection of family health history by patients and health-care providers remains an important and inexpensive screening tool available to the general public for evaluating individual genomic risks ${ }^{18}$ that is too often not attempted, inadequately collected, and/or insufficiently interpreted. This lack of proper documentation results in the inability to spot and understand familial patterns that may impact health. Successful dissemination, understanding, adoption, and adherence to genomic health recommendations will require an elevation of the genomic literacy of the public in the context of public health genomics, ${ }^{19}$ to promote the appropriate translation of the new science of genomics into health benefits to individuals and populations, and to evaluate the impact of genomic information on health care and disease prevention. ${ }^{20}$

Illustrating these points, Vicky J. Cardoza, MPH, of the National Council of La Raza, and Maria S. Gomez, RN, MPH, of Mary's Center in Washington, D.C., presented their experiences in assessing knowledge, perceptions, and behavior around genetic health and genetic health services during and after pregnancy among Latinos and their health-care providers in Washington, DC. ${ }^{21}$ Data analysis from focus groups and indepth interviews suggest that their patient population, including Latinos and other underserved communities, has little or no exposure to genetic health services, procedures, or their benefits during and after pregnancy. When genetic services were received, women perceived the information as confusing, worrisome, and nonactionable. Patients expressed difficulty in tracking their family health history and lacked social support to cope with genetic diseases and linguistic challenges. ${ }^{22}$ When asked about the most effective way to obtain information about genetic health, the health-care provider was identified as the most trusted source of information. Although their health-care providers understood the importance of genetic health services, they were unable to meet their patients' needs for genetic health-care services due to self-reported limited knowledge of genetics and genomics and lack of educational resources. In this regard, training opportunities targeted to health-care providers can build capacity and genomic knowledge to facilitate genomic health literacy of the public and the translation of genomic research to clinical care in a variety of settings. ${ }^{16}$ 
Similarly, Taura L. Barr, PhD, RN, and Patricia A. Crawford, MS, CHES, of West Virginia University discussed their joint project to identify and explore the genomic health literacy of rural underserved communities. Members of rural Appalachian communities who participated in three community forum settings expressed little knowledge of genetics and were unable to articulate what genomics is and why it matters. Lay audiences associated genetics with chronic disease and chronic disease management but not with disease prevention. They had few tools to interpret genetic risk concepts and understand gene-environment interactions. For example, the term "environment," was perceived as related to the physical world and nonactionable (i.e., water contamination, air pollution) but not related to lifestyle choices (i.e., impact of diet, smoking, or stress management on health).

In ensuing discussions, the participants agreed that the low health literacy and low genomic health literacy found during the Community Conversations are patent but hardly unique to these communities: instead, they are important roadblocks for the translation of genomics for many communities experiencing health disparities and low income and education. The data collected from these Community Conversations-although not necessarily generalizable to other populations and/or settings-nevertheless reinforce the importance of developing and evaluating culturally and linguistically appropriate educational materials and of using community-based participatory research as a method to explore the implementation of genetic and genomic education programs within the context of family, culture, and community history in all groups and populations in the United States.

A number of strategies to engage diverse communities in conversations around genomics and genomic health were suggested. These included partnerships of researchers and educators with federally qualified health centers, health fairs, home visit programs, newborn screening programs, first prenatal visit programs, lead exposure screening programs, parent-teacher association meetings, and faith-based organizations. The consensus was that community-based approaches can be highly effective to engage the public.

\section{THE CHALLENGE OF GENOMIC SCIENCE LITERACY}

The Genomic Science Literacy Session began with Louisa A. Stark, PhD, of the University of Utah and David A. Micklos, $\mathrm{PhD}$, of the Dolan DNA Learning Center, Cold Spring Harbor, NY, providing an overview of students' and teachers' genetic and genomic science literacy in the K-12 education system. Students are interested in genomic sciences but do not build an understanding of genes, DNA, chromosomes, proteins, and traits across multiple biological organization levels as they advance from grade to grade. ${ }^{23}$ Exacerbating the situation are poor national and state genetics standards that focus almost exclusively on Mendelian genetics. ${ }^{24}$ The new National Research Council Framework for K-12 Science Education, which will serve as the foundation for new K-12 science education standards for high school students over the next decade, brings more focus to genes, DNA, and genetic processes than previous national standards but places insufficient emphasis on genomics, and gene-environment interactions. ${ }^{25}$ Teachers, who share many of the same misconceptions around genomics and genetics as their students, have limited opportunity to update their skills and little access to genomic science curriculum materials that can be used to improve learning in all students. ${ }^{26}$ Highlights from focus groups held by the National Human Genome Research Institute with formal and informal K-12 educators echoed many of the roadblocks expressed by Dr Stark and Dr Micklos. These included lack of funding and curriculum materials, inadequate textbooks, standardized testing, time constraints, and rooted misconceptions (i.e., genetic fatalism, or believing that specific genetically predetermined outcomes are not avoidable, no matter what is done) ${ }_{,}^{23}$ which all together hinder teaching and learning about genetics and genomics.

Effective engagement strategies for K-12 audiences identified by the participants in the workshop included topics such as family health history, gene-environment interactions, and the ethical, legal, and social implications of genomics. These are some of the most universally appealing concepts to engage middle and high school students in genomics. School-based health education programs may offer untapped opportunities to engage with youth in genetic and genomic health topics.

Beyond the classroom, museums, science centers, mobile labs, Web-based teaching resources, and other nonacademic settings can play an important role in bringing genomic science closer to the public and extending student learning to family learning. ${ }^{27}$ Of note, genomic databases store vast amounts of high-throughput data and analysis tools that are often freely accessible, offering substantial opportunities for citizen science research, in the form of projects conducted solely by students and their teachers, or in guided partnerships with professional scientists. When presented with the opportunity, teachers and students respond with enthusiasm to sophisticated educational challenges based on bioinformatics interfaces that are conducive to user-friendly, hands-on research. To capitalize on this potential, Dr Micklos recommended researching classroom experiments that can be scaled up to reach communities of students and teachers, and investing in more student-scientist partnerships.

\section{THE ROLE OF MEDIA IN GENOMIC LITERACY}

Ending the day, Bruce A. Fuchs, $\mathrm{PhD}$, of the National Institutes of Health (NIH) Office of Science Education led the Genomic Literacy and Media presentation. Dr Fuchs presented national data that show that 15-year-old students in the United States perform poorly as compared with their international peers according to the "Programme for International Student Assessment" (http://www.pisa.oecd.org/) survey, which is used to track and compare math and science performance by high school students in participating countries and economies. Researchers and educators interested in promoting genomic science literacy must be challenged to develop their programming while embracing 
Table 1 Research opportunities to advance genomic literacy for the general public

\section{Research opportunities for studying genomic health literacy \\ Integrate patient genomic literacy studies into genomic medicine initiatives and into ethical, legal, and social implications research programs; \\ Research the use of family health history as a clinical tool; \\ Study how to improve the public's ability to understand probability and risk as genetic- and genomic-related concepts, as well as how to best present this information; \\ Encourage new research partnerships with state governments, community-based organizations, and private companies}

Research opportunities for studying kindergarten to grade 12 genomic science literacy

Develop reliable and validated measures to assess students' understanding of genetics and genomics concepts;

Identify common misconceptions and roadblocks in genetic and genomic education:

Evaluate students' retention of key ideas via longitudinal studies;

Study the use of informal education to educate the public;

Promote community-based participatory research in public genomic literacy

Research opportunities for studying the role of media in genomic literacy of the public

Study communication of key genomic health messages;

Study use of new media and new technologies to disseminate genomic information to the public;

Study the language of genomics;

Study strategies to effectively engage the public;

Support research on public perceptions about genomics

new educational and new media tools. These include (but are not limited to) websites; podcasts; blogs; Facebook; Twitter; Technology, Entertainment, Design talks; cognitive tutors; and authentic simulations.

The participants agreed that currently we know little about the channels available to the public to access genomic information, whether the genomic information they find is correct and at an accessible level, or if they are interested in knowing more about this science. However, a general concern was expressed that scientists often use jargon and lack training in communicating with the media and lay audiences. ${ }^{28}$ Likewise, popular entertainment and media often perpetuate scientifically incorrect genetic and genomic terminology such as the concept of a "gene for x" instead of "genetic variation in the gene that causes $\mathrm{x}$ " or "the contribution of the genetic variation, together with environmental factors, that cause $\mathrm{x} .{ }^{\prime 29}$

Considering that almost half of the US adult population have limited health literacy, ${ }^{7}$ a recurrent theme in the group discussions was that it is imperative to determine and evaluate culturally and linguistically appropriate genetic and genomic terminology and messages. Educational materials and messages (oral, printed, or posted online) must be pilot tested and validated by members of an intended audience before wide distribution. It was suggested that cancer education programs, which currently lead the way in weaving genetics and genomics information into health messages, offer a special area of effectiveness research focus.

In addition, the need to research storytelling, or the use of personal stories to illustrate relevancy of genomics concepts to real people, was frequently mentioned as possibly helping the public understand how this information could be of value for future health care and family decisions. Research on the use of new media and new technologies to effectively assess genomic literacy and/or disseminate genomic information to the public must also be supported (Table 1). For example, social media create both research and information dissemination opportunities through analyses of recurrent themes in blogs and online community conversations around genomic health and genomic disease.

\section{DISCUSSION}

A goal of this meeting was to identify research opportunities to advance genomic literacy in our society. The participants in the workshop agreed on four overarching research needs for the field:

1. Support research to define the knowledge needs of the public. An imperative need for the field is to develop and research a broad-based set of genomic literacy competencies and benchmarks that captures not what the public should know about genomics but rather what they should be able to do using their knowledge, skills, and attitudes about genetics and genomics. Focus must be kept on the formulation of overarching learning objectives needed to make personal and family health decisions, rather than producing a detailed list of genomic and genetic knowledge and skills. Efforts have to be inclusive to define what the public wants to know about genetics and genomics, what would be useful for the public to know under specific circumstances, and the context in which the public would accept this information, including what types of education may lead to health behavior changes.

2. Conduct research on best education practices for the public. Systematically mining, annotating, and aggregating into a database what has already been done in the area of genomic literacy can assist health-care providers, researchers, educators, grassroots community organizations, and others interested in elevating the genomic literacy of the public. A visible and freely accessible online repository of robust methodologies, assessment tools, and protocols to increase genomic literacy must be created, including an evaluation component to understand why successful initiatives work and if they can be scaled up from local outreach to broader audiences.

3. Generate short-term and long-term national "genomic literacy assessment" tools. Such tools are particularly needed for establishing the right metrics for the field of genomic literacy and to systematically document progress over time. In the short term, it would be possible to capture practical and 
reliable information about genomic health literacy by adding a number of targeted questions to ongoing national health interview surveys. In the long term, it is critical to invest in developing a tool for standardized, longitudinal tracking of the public's understanding of genetics and genomics. This could be done annually, or biannually, in a manner analogous to the Programme for International Student Assessment and Trends in International Mathematics and Science Study surveys.

4. Establish a Genomics Education National Conference. A recommendation to support a stand-alone genomic literacy conference or one in connection with existing forums such as the American Society of Human Genetics, American College of Medical Genetics and Genomics, National Coalition for Health Professional Education in Genetics, or Genetic Alliance annual conferences as a means to promote crossfertilization of ideas, research, and resources among educators, researchers, community-based programs, health departments, health-care providers, and others. This would provide a forum for resource developers to cultivate multidisciplinary partnerships and build communities, and to periodically chart progress in the field.

In addition, a number of research recommendations were specifically targeted to supporting genomic health literacy, K-12 genomic science literacy and the role of media (Table 1). Among the recommendations, more research on family health history merits special mention, given that it remains the most effective, least expensive tool available to the public to assess personal disease risk. ${ }^{18}$ Family health history used as a clinical tool can empower the public with a new understanding of health as it relates to their genetic heritage, including the connection between genetics, their family, the inheritance of health and disease, and the influence of environment. Even when theoretical knowledge of genomic science is low, family health history awareness effectively elevates the public's genomic health literacy because it improves their decision-making skills, leading to better personal and family health decisions in the context of everyday situations. ${ }^{30,31}$

Family health history is not without roadblocks. Health-care providers generally do not collect adequate family health history information in clinical practice. For some populations, family history is unknown or too sensitive to be discussed. Family structures and family practices vary among cultures. For instance, in some communities, full family status may be routinely extended beyond the biological family to other community members. Systematic research is needed on the impact of previous demonstration projects such as the US Surgeon General's "My Family Health Portrait" tool (https://familyhistory. hhs.gov/). ${ }^{32}$

Some research gaps around family health history identified at the workshop include how to integrate gene-environment interactions into family histories for an accurate assessment of disease risk, and the development and testing of tools so that the public and health-care providers can interpret family health history into actionable information. This could include programs that provide health-care practitioners tangible incentives for gathering and using family health history, such as compensation based on health outcome metrics.

\section{SUMMARY}

Genomic medicine will touch virtually every individual in the United States in the forthcoming generations. The public encompasses many different communities, and the interface with genetics and genomics changes in each stage of the life cycle of each person. Stakeholders present at this meeting identified promoting public understanding of the role of genomics in human health as an important cross-cutting goal for the realization of the promise of genomic medicine. Preparing the public to make educated personal and family health decisions in a time of rapidly evolving genetic and genomic knowledge will require new partnerships between the education system, healthcare systems, government, community advocacy organizations, consumers, and the media. Community-based participatory research is recommended to determine the specific needs and the most effective way to approach each audience. The meeting provided a research agenda to advance genomic literacy in our society, including recommendations on how to meet the current genomic literacy challenges and how to build toward integrating genetics and genomics into better health outcomes.

\section{SUPPLEMENTARY MATERIAL}

Supplementary material is linked to the online version of the paper at $h$ ttp://www.nature.com/gim

\section{ACNOWLEDGMENTS}

The authors thank Jonathan Gitlin, Jeannine Mjoseth, Carla L. Easter, and Jeffre Witherly of the National Human Genome Research Institute for their contribution to developing the program of the Genomic Literacy Workshop and their constructive feedback to the report; and Louisa A. Stark (Genetic Science Learning Center, University of Utah), David A. Micklos (Dolan DNA Learning Center), Bruce A. Fuchs (NIH Office of Science and Education), and Deborah Bowen (Boston University School of Public Health) for their keynote presentations demonstrating the genomic literacy challenges faced by the public. The Community Conversation projects were invaluable for exploring community opinions and attitudes about their constituencies' genomic literacy needs. The authors are grateful to Vicky J. Cardoza and Alejandra J. Gepp (National Council of la Raza) and Maria S. Gomez (Mary's Center in Washington, DC) and their communities for their collaboration and participation in the workshop; and to Taura L. Barr and Patricia A. Crawford at West Virginia University's Prevention Research Center for organizing the community genomics forums in Mount Hope, Kimball, and Grantsville, WV. T.C., K.A.K., N.L., and J.E.R. belong to Genomic Literacy Workshop Advisory Committee.

\section{DISCLOSURE}

T.C. is supported by the Office of Public Health Genomics, Centers for Disease Control and Prevention, and has been 
funded by R25RR-022703 from the National Center for Research Resources, NIH. K.A.K. is funded by grants R01 CA168608 and 3U54CA153460-03S1, National Cancer Institute; R21 HS020309, Agency for Healthcare Research and Quality; P50 CA95815 and P30 DK092950, NIH; and U58 DP0003435, Centers for Disease Control and Prevention. N.L. is supported by NIH Science Education Partnership Awards (SEPA) grant \#8R250D010981. J.E.R. at AAAS Project 2061 is funded by National Science Foundation (NSF) grants to promote science literacy since 1997, most recently to continue to support the Atlas of Science Literacy (ESI 0103678) and to create next-generation science curriculum materials (ESI 0227557) and science literacy assessment tools (ESI 0352473). The remaining authors declare no conflict of interest.

\section{REFERENCES}

1. Smerecnik CM, Mesters I, de Vries NK, de Vries H. Educating the general public about multifactorial genetic disease: applying a theory-based framework to understand current public knowledge. Genet Med 2008;10:251-258.

2. Literacy $\mathrm{CoH}$. Health Literacy: A Prescription to End Confusion. The National Academies Press: Washington, DC, 2004.

3. Standards NCOSE, Assessment, Council NR. National Science Education Standards. The National Academies Press: Washington, DC, 1996.

4. Green ED, Guyer MS. Charting a course for genomic medicine from base pairs to bedside. Nature 2011;470:204-213.

5. Bonham VL, Citrin T, Modell SM, Franklin TH, Bleicher EW, Fleck LM. Community-based dialogue: engaging communities of color in the United States' genetics policy conversation. J Health Polit Policy Law 2009;34:325359.

6. CDC/ATSDR Committee on Community Engagement., (U.S.) CfDCaP. Principles of Community Engagement, 2nd edn. Centers for Disease Control and Prevention: Washington, DC, 2011.

7. Kutner M, Greenberg E, Jin Y, Paulsen C. The Health Literacy of America's Adults: Results From the 2003 National Assessment of Adult Literacy. National Center for Education Statistics, National Center for Education Statistics: Washington, DC, 2006.

8. Syurina EV, Brankovic I, Probst-Hensch N, Brand A. Genome-based health literacy: a new challenge for public health genomics. Public Health Genomics 2011;14:201-210.

9. Lanie AD, Jayaratne TE, Sheldon JP, et al. Exploring the public understanding of basic genetic concepts. J Genet Couns 2004;13:305-320.

10. Lea DH, Kaphingst KA, Bowen D, Lipkus I, Hadley DW. Communicating genetic and genomic information: health literacy and numeracy considerations. Public Health Genomics 2011;14:279-289.

11. McBride CM, Bowen D, Brody LC, et al. Future health applications of genomics: priorities for communication, behavioral, and social sciences research. Am J Prev Med 2010;38:556-565.

12. Welch V, Tugwell P, Petticrew M, et al. How effects on health equity are assessed in systematic reviews of interventions. Cochrane Database Syst Rev 2010;12:MR000028.
13. McBride CM, Koehly LM, Sanderson SC, Kaphingst KA. The behavioral response to personalized genetic information: will genetic risk profiles motivate individuals and families to choose more healthful behaviors? Annu Rev Public Health 2010;31:89-103.

14. Marteau TM, Dormandy E, Michie S. A measure of informed choice. Health Expect 2001;4:99-108.

15. Kaphingst KA, McBride CM, Wade C, Alford SH, Brody LC, Baxevanis AD Consumers' use of web-based information and their decisions about multiplex genetic susceptibility testing. J Med Internet Res 2010;12:e41.

16. Feero WG, Green ED. Genomics education for health care professionals in the $21^{\text {st }}$ century. JAMA 2011;306:989-990.

17. Korf BR. Genetics and genomics education: the next generation. Genet Med 2011;13:201-202.

18. Guttmacher AE, Collins FS, Carmona RH. The family history-more important than ever. N Engl J Med 2004;351:2333-2336.

19. Khoury MJ. Public health genomics: the end of the beginning. Genet Med 2011;13:206-209.

20. Khoury MJ, Bowen MS, Burke W, et al. Current priorities for public health practice in addressing the role of human genomics in improving population health. Am J Prev Med 2011;40:486-493.

21. Gepp AJ, Cardoza V, Pompa D, Hurle B, Gomez M. Genetic services and literacy in Latino communities: a community conversation addressing maternal and child health needs. American Public Health Association Annual Meeting, San Francisco, CA, 27-31 October 2012.

22. Forman $A D$, Hall MJ. Influence of race/ethnicity on genetic counseling and testing for hereditary breast and ovarian cancer. Breast J 2009;15(suppl 1):S56S62.

23. Duncan RG, Reiser BJ. Reasoning across ontologically distinct levels: students' understandings of molecular genetics. J Res Sci Teach 2007;44:938-959.

24. Dougherty MJ, Pleasants C, Solow L, Wong A, Zhang H. A comprehensive analysis of high school genetics standards: are states keeping pace with modern genetics? CBE Life Sci Educ 2011;10:318-327.

25. Standards CoCFftNK-SE, Council NR. A Framework for K-12 Science Education: Practices, Crosscutting Concepts, and Core Ideas. The National Academies Press: Washington, DC, 2012.

26. Stark LA, Pompei K. Winner of Science Prize for Online Resources in Education Making genetics easy to understand. Science 2010;327:538-539.

27. Micklos D, Lauter S, Nisselle A. Essays on science and society. Lessons from a science education portal. Science 2011;334:1657-1658.

28. Condit CM. How geneticists can help reporters to get their story right. Nat Rev Genet 2007:8:815-820.

29. Bates BR, Templeton A, Achter PJ, Harris TM, Condit CM. What does "a gene for heart disease" mean? A focus group study of public understandings of genetic risk factors. Am J Med Genet A 2003;119A:156-161.

30. O'Leary J, Edelson V, Gardner N, et al. Community-centered family health history: a customized approach to increased health communication and awareness. Prog Community Health Partnersh 2011;5:113-122.

31. Khoury MJ, Feero WG, Valdez R. Family history and personal genomics as tools for improving health in an era of evidence-based medicine. Am J Prev Med 2010;39:184-188.

32. Facio FM, Feero WG, Linn A, Oden N, Manickam K, Biesecker LG. Validation of My Family Health Portrait for six common heritable conditions. Genet Med 2010;12:370-375. 